\title{
1. The crude oil market and its driving forces
}

The global crude oil market has some specific features that are often debated and of which some are of primary and some of secondary importance. In order to understand the oil market throughout this work, we briefly consider these issues, review the corresponding literature and locate them with respect to our specific research goal.

\subsection{THE IMPORTANCE OF CRUDE OIL: SOME FACTS}

The global market for crude oil can be characterized by several features worth mentioning. They concern production and consumption patterns, price development and the importance of oil as an energy source. We briefly refer to each of them in turn. Oil production with data from the Energy Information Administration (EIA) is depicted in panel (a) of Figure 1.1. Obviously, worldwide crude oil output has featured a more or less steady long-run increase since 2000 . While OPEC production features several fluctuations, production of the rest of the world follows a rather stable path. At the end of 2014, OPEC accounted for about 38 per cent of total world oil production. Panel (b) exhibits the demand side, that is, crude oil or petroleum consumption. Global consumption has as well continuously risen since 2000. Organisation for Economic Co-operation and Development (OECD) countries consumed slightly less oil in 2014 than they did in 2000. Conversely, non-OECD countries faced a strong and constant increase during the same time span and even outpaced OECD consumption in 2014.

Daily crude oil spot prices of type West Texas Intermediate (WTI) are plotted in Figure 1.2. In 2002, the price started to rise continuously until mid-2008, aside from an interrupt in 2006. The sharp price drop after the price peak in 2008 coincides with the outbreak of the global financial crisis. However, at the beginning of 2009, the price started rising again and stayed around 100 dollars. In the second half of 2014, it sharply decreased and has oscillated around 40 dollars since then. Even though our data window 
Panel (a) World, OPEC, and non-OPEC crude oil production

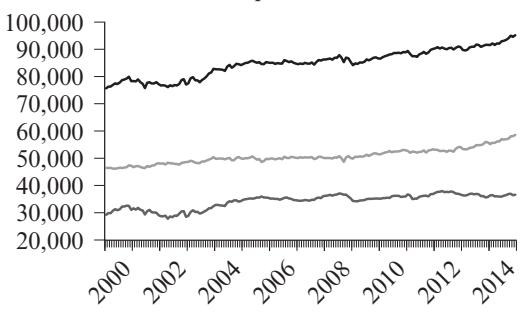

— World production
- OPEC production
— Non-OPEC production

Panel (b) World, OECD and non-OECD petroleum consumption

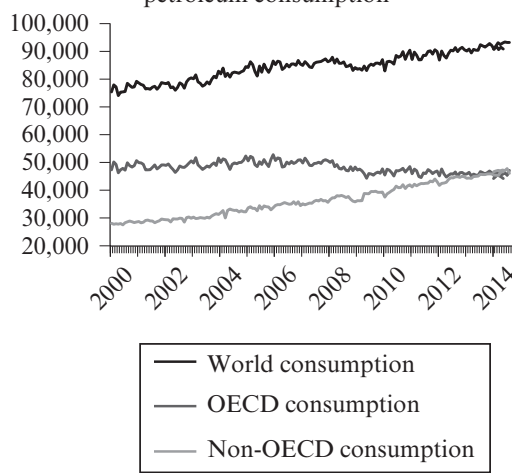

Source: Energy Information Administration (2015b). International Energy Statistics.

Figure 1.1 Global oil production and consumption (in thousand barrels per day), 2000-14

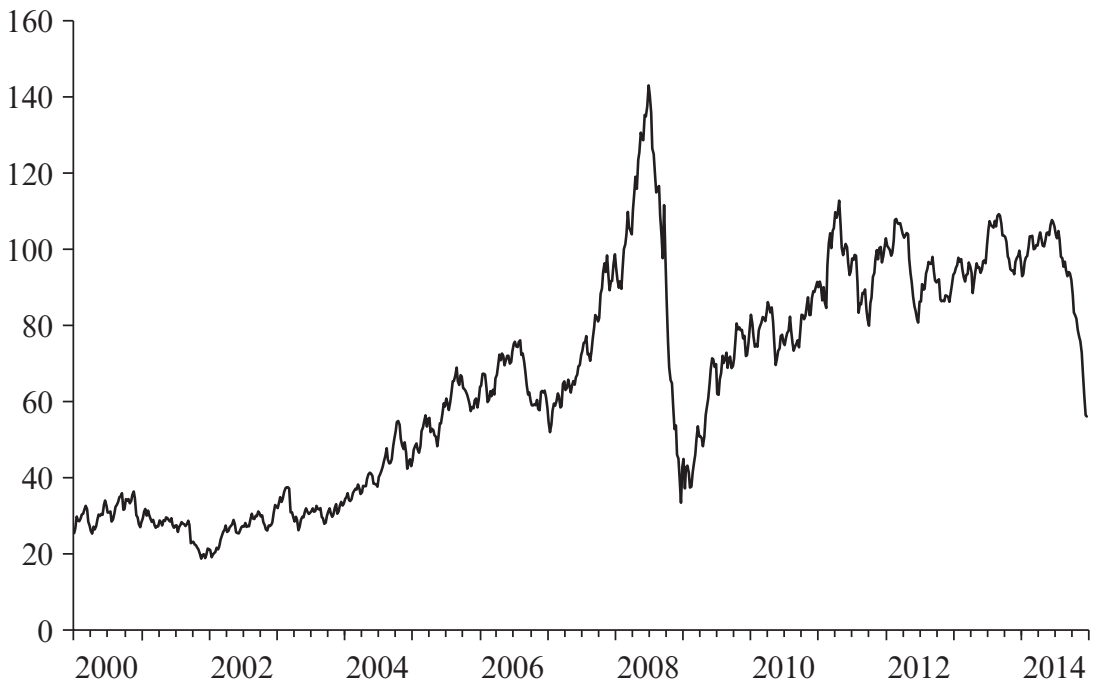

Source: Energy Information Administration (2015a). Petroleum and other Liquids.

Figure 1.2 WTI crude oil spot price per barrel in US dollars, 2000-14 


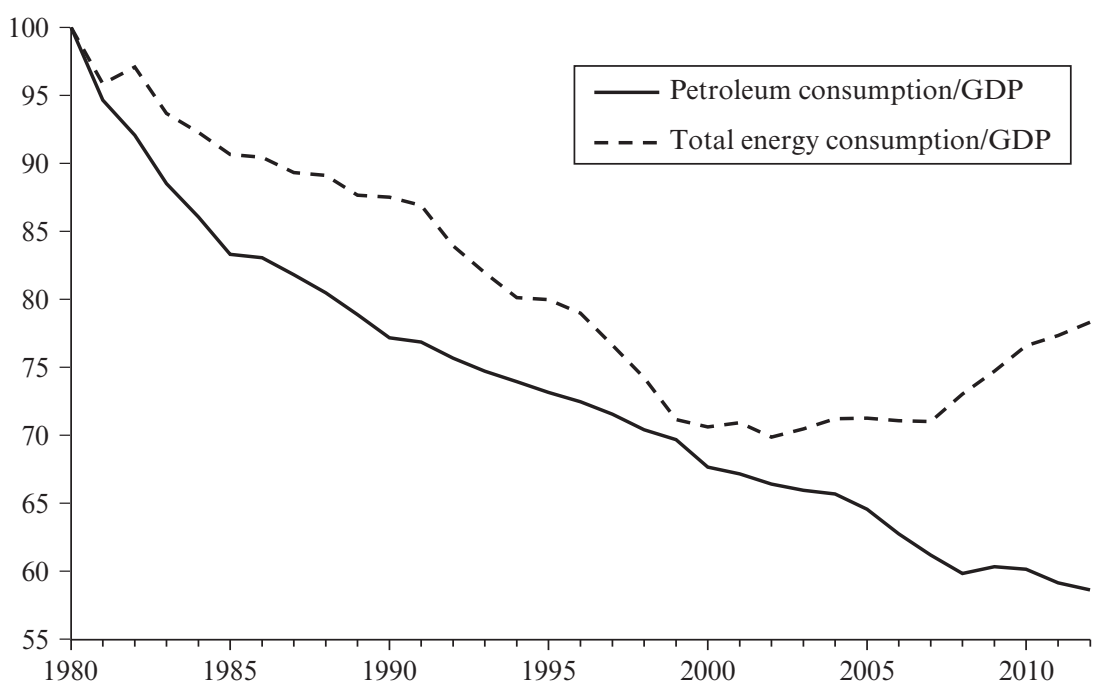

Sources: Energy Information Administration (2015b). International Energy Statistics; World Bank (2015). World DataBank.

Figure 1.3 Global petroleum and total energy intensity of output, $1980-2012(1980=100)$

already ends in 2014, the last phase of the price decline will be of great analytical interest. At the moment of completion of this book, the price persists in being low.

Relating oil consumption to total output, we get a measure of the oil intensity of the economy. Considering a longer time horizon since the 1980 s, it can clearly be seen from Figure 1.3 that the oil intensity of output has remarkably decreased since. The pattern of total energy intensity of output, to wit, the intensity after including natural gas, coal and electricity, in addition to oil, is much less clear. It features a declining path from 1980 until 2000. From then on, intensity stagnated first and has again risen since. Without investigating this trend further, there are two remarks to make. First, like the graphs with oil production and consumption, the indexes of oil and total energy intensity only identify the crossing point of the supply and demand sides of the oil and total energy market, respectively (once we consider the denominator of the ratio, to wit, GDP, as given). The long-run decline of oil intensity neither says that the demand side of the oil market has become weaker relative to total output evolution, nor that the supply side has faced fixed constraints holding oil consumption down. Since data only reveal the final market result, we cannot say 
anything about the underlying market forces. It may be that with different stances of energy, economic or monetary policy oil intensity would have declined much more or much less over this time. Second, the recent rise in total energy intensity of output shows that a decrease in relative energy consumption over time is far from being the predetermined outcome. It is in this place that economic analysis is required to detect underlying forces that are not visible in data. In this regard, the connection of crude oil to other energy sources plays a crucial role.

While it is generally not denied that crude oil is a central fuel driving the global economy, it should be set in relation to other energy sources. Even though the share of natural gas, coal and electricity has been growing over the last 50 years, crude oil is still the most important fuel and accounts for about one-third of total energy consumption in 2012 (EIA, 2015b).

A large body of literature has been and still is produced concerning the role of crude oil, not only in comparison to other energy sources but also with respect to the whole macroeconomy. As this is not the centre of our work, we just give a very short summary of how research judges the importance of crude oil in the economy. In general, a rising oil price is associated with distorting effects on economic production of oil-importing countries. It is argued that GDP declines while inflation tends to increase (see, for instance, Sill, 2007). Yet, this is too absolute a conclusion as the combination of missing economic growth and high inflation was observed in the 1970s but not since. As Kilian (2010b, p. 14) remarks, an isolated recessionary oil price shock is expected to lead to deflation rather than inflation.

High oil prices can affect the economy on both the supply and the demand side as summed up by Kilian (2010b, pp. 5-10). A higher oil price raises input costs for producers and as such represents a supply-side constraint. On the demand side, households face a tighter budget constraint after having paid the bill for energy consumption such that there is less money left to spend for other goods. An additional and specific channel is argued to lie in monetary policy. Thereby, recessionary effects are not directly produced by high oil prices but rather by contractionary monetary policy aimed at stopping inflationary pressures that are themselves due to the change in oil prices (see, for example, Bernanke et al., 1997). Yet this argument is criticized to hold only if monetary policy is not anticipated (see Carlstrom \& Fuerst, 2005). Otherwise, accommodating actions by the central bank are suggested to bring about the same results.

Most researchers find that the effects of oil price shocks on the economy have decreased in the 2000s compared to the 1970s (see Blanchard \& Galí, 2007; Kilian, 2010a). ${ }^{1}$ However, the explanations for this observation differ. Blanchard and Galí (2007) consider a high oil price as an exogenous shock. According to their analysis, first, the shocks went along 
with different additional effects in the 1970s than in the 2000s. Second, unsurprisingly in face of their neoclassical or new Keynesian background, reduced wage rigidities have lowered the effect on output and inflation. Third, monetary policy has become more credible and thus more able to keep inflation expectations low. Fourth, the share of oil in production, that is, oil intensity, has decreased, which limits potential effects of an oil shock a priori. Segal (2011) argues that the pass-through of the oil price decreased over past decades, which lowered the need of contractionary monetary policy and hence reduced harmful effects on the economy.

Kilian (2010a, 2010b) strongly criticizes the assumption of exogenous oil price shocks. Their effect on the economy and the way the monetary authority should respond to them depend on the cause of the oil price change, which is itself an endogenous variable. If it is a supply disruption due to, say, a war in an oil-producing country, the high oil price effectively tends to affect economic performance negatively to a certain extent. In this case, the central bank should loosen monetary conditions despite potential inflationary pressure in order to counteract a recession. Otherwise, it would just deepen it. On the other hand, if it is a high oil demand at home or abroad leading to a higher oil price, there is no recession to expect since the oil price is itself just a symptom of a boom period. It is in this case that inflation should be treated by contractionary monetary policy. The recession follows once the demand boom decelerates (ibid., 2010a, p. 81). The need for different monetary policy responses to different kinds of oil price shocks is confirmed, for example, by Bodenstein et al. (2012). The decreasing effect of high oil prices therefore is to ascribe to their different origins.

Even though literature finds a decreasing impact of oil price changes on production, it does not mean that the relevance of crude oil is declining as well. Besides its impact on GDP growth rates, its character as a nonrenewable fuel and the fact that fossil energy sources still account for more than 80 per cent of total energy consumption make it highly important to analyze the market for crude oil, specifically against the background of climate change.

\subsection{CRUDE OIL AS AN EXHAUSTIBLE AND FOSSIL RESOURCE}

The first question asked in common discussions about oil is the one regarding how much of it is left in the world. Crude oil is exhaustible. This is the characteristic standing in the spotlight of research on, and political debates about, climate change and resource security (see, for instance, International Energy Agency (IEA), 2012, pp.97-101). Oil - together 
with other non-renewable energy sources like natural gas and coal - is the central fuel driving global production. The limitation of oil reserves in the underground and the numerous threats of climate change will require humanity to search for new sources. A large part of debate considers the basic task as a technological one requiring the replacement of fossil fuels by renewables (see Hamilton, 2012). Other voices go much further by suggesting that the need for more energy efficiency and saving in energy consumption will require fundamental changes in social and economic organization. According to these arguments, the difficulty is not primarily of a technological nature the resolving of which would allow business as usual. As the best-known among other institutions and individual scientists, the Club of Rome identifies permanent growth in economic output as the most important cause of rising energy consumption and worsening environmental damages (Meadows et al., 1972, pp.38-44, 54-87). In its original and famous book The Limits to Growth (Meadows et al., 1972), it predicts the collapse of the existing world economy and the current way of living in developed countries if no change in the organization of human living takes place. The reason for this sinister perspective is the contradiction between economic growth and natural limits given by ending resources. One day, the world will reach peak oil, that is, the maximum possible crude oil production. From that point onwards, it cannot but follow a steady decline sooner or later owing to diminishing oil reserves. Once the last drop of oil is burnt, the economy breaks down.

This prediction has not become reality up to now and we do not know the time horizon of the further development. Even though such analyses address problems of greatest seriousness, which should not be ignored even though the collapse has not yet become reality, the basis of the Club of Rome's and others' predictions is not able to overcome some complex economic issues. Predicting linearly or exponentially increasing energy consumption ignores price effects. If fossil fuels become scarcer, their price is likely to rise which leads to new factor allocation. For example, alternative energy production replaces crude oil partially. This has a declining effect on the oil price. As another example, higher expenditures for research and development in the field of renewable energy and energy efficiency may make alternatives to fossil fuel less expensive and hence more competitive. Hence, whether the end of fossil resources ever takes place and, if this should be the case, whether the passing over to a new way of energy production takes the form of chaos or collapse, is highly uncertain.

Despite uncertainty, such reflections are important, especially from a normative point of view. In positive economic analysis, the role of resource limitation is somewhat different. It can be seen as an outermost constraint within which the economics of the crude oil market take place. Once this 
constraint becomes binding, we face a situation where varying demand meets constrained supply. In the case of demand growth, this leads to a potentially strongly - rising oil price. It is this case to which the well-known 'Hotelling rule' of the optimal consumption rate of exhaustible resources is applied (Hotelling, 1931). The classical economists have already regarded price-building in markets for limited goods. This has led to the definition of rent, to wit, a form of extra profit earned by the owner of such a resource, which used to be land or metals in the eighteenth and nineteenth centuries (see, for instance, Marx, 1894/2004, pp.602-788; Ricardo, 1821/1923, pp. 52-75; Smith, 1776/1976, pp. 160-275). In post-Keynesian literature, in line with classical economists, limited natural resources are also distinguished from other, unconstrained, goods. While the latter are argued to face a horizontal long-run supply curve, the former behave differently, since rising demand is not necessarily satisfied by equally increasing supply at a stable price (Kalecki, 1987, p. 100). Importantly to note, the supply constraint cannot automatically be set equal to all proven reserves in the world. Not all reserves are profitable at all oil price levels. Those reserves that are difficult to access face a higher production cost and thus are only extracted if a sufficiently high oil price guarantees profits to producers. A rising price may give an incentive to intensify exploration activities. This shifts the constraint outwards even though it might have been considered as fixed before. It is therefore not possible a priori to determine the definite total volume of oil reserves that is relevant for our economic investigation. Furthermore, it may happen that the constraint of exhaustion becomes partially binding. Oil might still be geologically available in abundance but it is only accessible if the oil price reaches a specific minimum level. The resource then is partially exhausted in the sense that it no longer exists at the hitherto low prices. This gives the supply curve again another form.

As long as demand can be satisfied by oil production without requiring a higher price, the limitation of total existing reserves is not relevant for market participants at that moment, that is, the outermost constraint of reserves is not binding. Hence, within this constraint, there are other limits that are relevant in the shorter term already before oil reserves run the fear of exhaustion. These are production capacities that can be fully utilized in a given situation such that higher demand raises the price. Additionally, oil companies and households may possess inventories that they use as a (personal) reserve in order to hedge against price changes. Once all inventories are sold or consumed they cannot serve as a buffer against price fluctuations anymore. Another reason for rising prices may lie in market power on the producer side. We can therefore say that, as long as oil reserves suffice to satisfy existing demand, crude oil shares the same features as any other product market. 
For these reasons, price changes should not precipitately be attributed to exhausting oil. Even though this is relevant without doubt in the long run, it is not necessarily true that a high oil price in a given situation is due to the absolute exhaustion of oil reserves. A case of absolute exhaustion occurs if the oil price keeps rising without there being a reaction on the supply side. Partial exhaustion is much more difficult to assess.

Concerning the present-day degree of absolute exhaustion of oil reserves, opinions differ widely. The IEA (2013, pp. 3-4) forecasts a declining production of conventional oil requiring the extraction of unconventional sources on the one hand, and a high oil price in 2035 on the other, to fill the gap between supply and demand. In contrast, for example, the Statistical Review of World Energy of British Petroleum (BP) (2015, p. 7) estimates that the ratio of global total oil reserves to annual global production has not only been constant but even slightly rising since the middle of the 1980s. In 2014, this ratio states that proven reserves are sufficient for 52.5 years of global production. Being aware of the wide area within which the technical and economic debate about long-term prospects takes place, we will have to find out how far they are in relevance when analyzing the connections between monetary policy and the global market for crude oil.

\subsection{THE ISSUE OF SPECULATION}

Let us now turn to the central debate where monetary policy comes into play as will be discussed in abundance in this work. This concerns the driving forces of the crude oil market. It may be fair to say that the largest amount of literature concerned with this topic concentrates exclusively on the oil price and ignores the effects that the price-driving forces have on oil quantities. Thereby, it centres on the question whether the oil price is only determined by supply of, and demand for, physical oil or whether speculation has a significant impact, too. The important point lies in our interest of how monetary policy affects the crude oil market through financial markets.

First of all, it is not easy to get a definite meaning of speculation. This may be one reason why a considerable part of research omits it. Yet, another one might be that the existence of speculation is not equally acknowledged by all economists. It will be seen in more detail in the next chapter that neoclassical economics in its proper sense does not leave room for speculation. Or, to put it at a little more length, it may be allowed to exist but it does not have significant effects on other variables. However, being convinced or not of the existence of speculation, it needs to be 
defined so that it can be tested. Kaldor $(1939$, p. 1) provides a definition in an influential paper:

Speculation [. . .] may be defined as the purchase (or sale) of goods with a view to re-sale (re-purchase) at a later date, where the motive behind such action is the expectation of a change in the relevant prices relatively to the ruling price and not a gain accruing through their use, or any kind of transformation effected in them or their transfer between different markets. [. . .] What distinguishes speculative purchases and sales from other kinds of purchases and sales is the expectation of an impending change in ruling the market price as the sole motive of action.

As another, contemporary source, Kilian and Murphy (2014, p. 455) determine speculation, in the specific case of crude oil, by 'treat[ing] anyone buying crude oil not for current consumption but for future use as a speculator from an economic point of view. Speculative purchases of oil usually occur because the buyer is anticipating rising oil prices'. These definitions should basically not be too controversial even though the authors mentioned belong to different schools of economic thought.

Yet, opinions differ with regard to the impact that speculation has on prices, quantities, economic activity, employment and economic stability. The issue becomes controversial at this point because it moves from the definition of speculation to its embedment into the economy. This act may still be positive but it is close to the somewhat normative judgement of whether speculation is beneficial to the economy and society or not. Kaldor $(1939$, pp. 2, 10) argues that speculation can be both price-stabilizing and price-destabilizing, depending on the magnitude of speculative activity and the range within which the price of the asset is moving alongside speculative influences. He outlines several conditions to be fulfilled in order for an asset to be traded speculatively. It must be fully standardized, durable, valuable in proportion to its bulk and it must be an article of 'general demand', that is, it must be an important good in the economy (ibid., p. 3). If so, then it becomes possible to bet on changing prices by accumulating or reducing the stocks of the relevant asset. The more speculators build stocks when they expect a higher price, the more speculation eventually affects the actual price (ibid., p. 7). Additionally, the more speculators change their price expectations in the face of a change in the current price, the more they raise or lower their stocks (ibid., pp. 8-9). By means of these two elasticities, the influence of speculation is assessed.

This theory is contradicted by other, mainly neoclassical, economists. Defending the 'efficient market hypothesis', yet to be discussed in more detail, they deny a significant impact of speculation on other variables. It is the efficient market as a whole that determines prices. Speculators who 
swim against the storm make a losing deal for sure, that is, they cannot beat the market (see Malkiel, 2003, p. 77). If anything, speculation is argued to be beneficial because speculative investment provides the liquidity necessary to allow not only faster price discovery but even guarantees the functioning of financial markets (Fattouh et al., 2012, p.4). Financial stability is therefore enhanced.

One may think that it is more appropriate to take newer conceptions of speculation than those of the first half of the twentieth century. However, as just seen, we cannot say that new research results have definitely abandoned older explanations. Even though Kaldor's (1939) theory is rather mechanical in some aspects and without ruling out other approaches here, we can keep it in mind for the remainder. It does not insist on the inevitable and permanent presence of speculation nor does it eliminate it a priori by theoretical assumptions. It just draws the mechanisms through which it may become effective. By testing for the existence and effectiveness of speculation, most authors more or less follow Kaldor's line of thought independent of whether they consider it as realistic or not.

Yet, in fact, assessing speculation empirically is quite difficult. In the case of producing companies, for example, it is seemingly clear that any intertemporal considerations or any exposure in financial contracts serve the purpose of hedging against future price fluctuations. Concerning crude oil, a corporation may accumulate inventories in order to smooth price hikes when sudden supply interruptions or demand growth take place. But what is the appropriate level of stocks in such a situation? The corporation's stock-building may as well have the effect of keeping the oil price higher than necessary. The line between hedging and speculating thus may often be difficult to draw. Another aspect of Kaldor's theory that is not fulfilled nowadays anymore is the argument that speculation is done by accumulating stocks. That is not wrong. We will as well argue that a high price tends to go along with higher inventories if it is to be driven up by speculation. Yet, as will become clear throughout our theoretical analysis, stocks do not necessarily have to be the cause of the speculative price change. They may as well and even more likely be the result of speculation. In our highly financialized economies, oil futures contracts are the object of interest for most speculators. Thereby, they are completely disconnected from the physical aspects of the underlying real asset. Hence, their owners are not at all concerned with the accumulation of stocks.

In contrast to other commodities, crude oil as a fossil fuel requires another specification. Kaldor (1939, pp. 10-11) argues that commodity prices are determined by 'supply price' in the long run, that is, by production cost and a certain profit share. To the degree that this supply price is known, the actual price should sooner or later come back to this level once 
it deviates from it. Yet, crude oil is not infinite and its possible exhaustion in the future may lead speculators to drive their price expectations upwards so that - if speculation is effective - the actual oil price is as well higher than it would be otherwise. Such expectations might be justified or not. But they have the potential to be relevant in both cases. Moreover, exhaustion does not allow for acting on the assumption of a constant supply price. The limitation of oil sources is thus an issue that makes speculation even more difficult to assess.

Before we start the detailed analysis of monetary policy, speculation and its impact on the market for crude oil, let us get an overview of the existing literature on these issues as a preliminary. Indeed, this literature has the same (or similar) starting points as our analysis. Some contributions emphasize monetary policy explicitly. The outstanding feature of the past years that turned its special interest to the crude oil market, is the price peak in 2008. Even though research on this single event may appear as quite specific, it contains nevertheless many features that help understand the market in general. In the course of our analysis, we will have a closer look at many of the following contributions.

The view that the crude oil market is merely driven by fundamental forces, to wit, supply by oil producers and demand by oil consumers, is briefly explained by Fattouh (2010, p. 14), who calls this rather simple approach the 'conventional framework': changes in the crude oil price trigger feedbacks from the supply and demand sides. The resulting oil price depends on price elasticities of oil supply and demand. The lower they are, the higher the oil price can rise or fall without being counteracted by supply and demand responses (ibid., p. 16). Among those contributors who deny any significant speculative influence on the oil price during the price hike of 2008, opinions differ again with regard to fundamentals. Some see the major cause of the price increase on the supply side, others on the demand side. One of the most influential articles published in the line of the fundamentals view is Kilian (2009b). By constructing a vector autoregression (VAR) model that allows for endogenizing the oil price, he finds that the price peak of 2008 is almost entirely explained by increasing demand.

In the context of demand-side considerations, the oil price peak is often ascribed to the fast-rising need for energy of emerging economies like those of China or India. In another paper, Kilian (2009a) tests for the impact of these two countries by taking GDP forecasts as the basis of the approach. The study finds that the two emerging economies are an important but by far not the only source of the price increase since forecast error corrections of OECD countries also explain a comparable fraction of the price. $\mathrm{Mu}$ and Ye (2011) sharply contradict the view of emerging economies' demand 
growth as a significant source of the relevant oil price increase. They focus on China as the most important of these countries. By means of a VAR, they provide evidence that an increase in China's oil imports does not have a significant effect on the real oil price.

The stance that the high oil price was caused by supply-side shortages is taken up by Kaufmann (2011) who strongly criticizes Kilian's (2009b) approach. Kaufmann (2011, pp.106-108) shows that, Kilian's demand variable is influenced by the oil price rather than the other way around. With respect to the supply side, he divides oil production into OPEC and non-OPEC output. While non-OPEC output was limited, OPEC oil production played the role of the marginal supplier which pushed up the oil price due to strategic behaviour (ibid., p. 108). Moreover, total capacity utilization increasingly approached the upper bound.

A growing body of literature considers the pure fundamentals view as insufficient. Another section denies any speculative influence but changes the approach in order to have a theoretical background on the basis of which speculation can be tested empirically. A theoretical model of speculation with an undefined asset is provided by De Long et al. (1990). As a crucial feature, they distinguish three types of investors and hence differ from basic neoclassical assumptions of homogenous agents or a single representative agent. There are rational informed investors who build expectations about the true value of the asset, which is postulated to be well defined. Passive investors buy when the price is low and sell when it is high. Feedback traders consider the price history of the preceding periods, invest when the price was rising in the past, and sell otherwise. The authors show how the price then can deviate from the asset's fundamentals value, such that a speculative bubble emerges. Tokic (2011) extends the De Long et al. (1990) model and applies it to the crude oil market. Producers and consumers basically have a price-stabilizing effect as they regulate oil inventories in order to smooth fluctuations. Passive investors who are in search of portfolio diversification and inflation protection, however, do not consider oil market fundamentals but, rather, use inflation rates and stock market risk as indicators to decide on oil purchases. They might therefore move the oil price, which attracts feedback traders. When the price is increasing, those agents who act on the assumption that the price always reverts to its fundamental value cannot but participate in the speculative bubble. If they continued pursuing their strategy of selling oil, that is, going short, they would suffer growing financial losses. Once feedback traders realize that the price is above the fundamental value, they start selling and the bubble bursts (Tokic, 2011, pp. 2057-2058).

Fattouh and Mahadeva (2012) present a neoclassical model with speculators, producers and consumers, that extends over two periods. Owing to 
agents' awareness of this fact, it becomes harder for large price deviations from fundamentals to occur, since changes in period 1 are counteracted in period 2. The term structure of the oil spot price can be tilted but it cannot be shifted (ibid., p. 16). Basically, however, the model allows for financialization when speculators raise their oil market exposure. Calibration with real data leads the authors to the conclusion that speculative activity may of course exist but that it affects the oil price only marginally. In contrast to this, Cifarelli and Paladino (2010) apply an Intertemporal Capital Asset Pricing Model (ICAPM) to the crude oil market and include the possibility of feedback trading. Empirical tests confirm significant positive feedback trading, which has itself a significant impact on the oil price.

Another theoretical model is developed by Alquist and Kilian (2010): a higher risk of future supply shortfalls raises the incentive to hold additional inventories today. This raises the oil spot price in relation to the futures price. Even though one may allow speaking about speculation in this case, the authors prefer the term 'precautionary demand' indicating that inventory accumulation merely serves hedging needs (ibid., p. 540). A precautionary demand component econometrically determined in Kilian (2009b) is tested for correlation with the futures spot spread and exhibits remarkable results but also fails for a part of the period considered (Alquist \& Kilian, 2010, p. 566).

Knittel and Pindyck (2013) construct a simple model of constant price elasticities of supply and demand, and test for the possibilities of speculation as well as its implied effects on the price of oil and inventories. They find that the actual pattern of the oil price can be replicated by fundamentals data so that there is no room for speculation.

A series of purely empirical contributions examines Granger causalities between the speculative activity and the crude oil price (see, for instance, Alquist \& Gervais, 2011; Büyükşahin \& Harris, 2011; Interagency Task Force on Commodity Markets (ITF), 2008). They usually employ net long futures positions of different categories of investors. It is assumed to be an appropriate measure of speculation. The studies get similar conclusions, namely, that changes in the crude oil price Granger cause changes in futures holdings of investors but that there is no significant Granger causality in the reverse direction. Stoll and Whaley (2010) investigate the impact of index investment on non-energy commodity futures prices and end up with an analogous conclusion.

Another study leads to opposite results. Tang and Xiong (2011) analyze the connection between different commodities with a focus on commodity indexes. Index investors are likely to behave according to Tokic (2011, p. 2056) insofar as they do not aim at exploiting the expected price change of a single asset but rather invest in commodities to diversify their portfolio 
and to protect against inflation. First, Tang and Xiong (2011) find that correlation between different commodity prices, for example, between crude oil and some selected non-energy commodities, increased over time and that the increase was more pronounced for index-traded commodities. These findings favour the view that commodity prices are influenced by speculation and thus may deviate from fundamentals. The latter differ with respect to each single commodity such that prices would differ as well, if fundamentals were the only determining variables.

A similar result is obtained by Büyükşahin and Robe (2011). They have access to disaggregated non-public data and test for co-movement of energy commodity and stock prices. The results suggest that correlation between the prices of the two markets increases with the presence of hedge funds that are active in both markets. If groups of financial investors are able to influence market performance of assets, then it is likely that these asset prices can deviate from fundamental values.

Lombardi and Van Robays (2011) use a VAR and introduce the oil futures price in addition to the spot price. The defined speculative shock and a precautionary demand variable are found to contribute to the spot price increase between 2000 and 2008 (pp. 25, 26).

In the same paper already mentioned above, Kaufmann (2011, pp. 109114) tests for the presence of speculation in the oil price by testing for the law of one price. He observes that the prices of two different types of crude oil, that is, the WTI five-month forward contract and the spot price for Dubai-Fateh, exhibit a cointegrating relationship. This relationship is found to break down in the period of strong price growth in 2007 and 2008. With two alternative approaches, this breakdown is confirmed. Evidence of such explanation gaps is not a direct confirmation but at least a hint of speculation.

Fan and $\mathrm{Xu}$ (2011) test for structural breaks in order to find evidence of how the price-determining variables of the crude oil price might have changed in the course of the 2000s. The overall result states that futures position variables are significant during the oil price growth before 2008 while the fundamentals variable is insignificant. After the price sharply drops, the fundamentals variable becomes significant while the speculative variables no longer have any explanatory power.

Lammerding et al. (2013) construct a bubble state-space model. They assume the oil price switches between two regimes, where in one it follows its true fundamental value while in the other it departs from that value, meaning that a speculative bubble is accumulating. Application of the model to real data shows that high bubble regime probabilities indicate price bubbles in the course of the run-up to the price peak in 2008 and again in 2009 when the price starts rising again. 
In literature where monetary policy is directly involved, speculation is often only implicitly discussed. A theoretical body to which debate often refers is provided by Frankel $(1984,2006,2014)$ and Frankel and Rose (2010). It says that interest rates affect the oil price through a couple of channels both on the supply and the demand side of the crude oil market such that contractionary monetary policy lowers the oil price (see, for instance, Frankel, 2006, p. 5). These channels will be discussed in more detail. Some papers test the theoretical implications and find mixed evidence (see Anzuini et al., 2013; Arora \& Tanner, 2013). An event-based study tests for the same effects of unconventional monetary policy on prices of commodity indexes between 2008 and 2010 and does not find significant results in favour of the underlying theory (Glick \& Leduc, 2011). Other studies employ high-frequency data to investigate intraday responses of oil prices to monetary policy shocks (see Basistha \& Kurov, 2015; Rosa, 2013). The motivation is that price responses within just a few minutes have a greater chance to be free of noise from other shocks. There are significant results suggesting that a negative interest rate shock raises oil prices. However, the results usually become insignificant when enlarging the framework to daily or monthly responses (Basistha \& Kurov, 2015, pp.95-102). This may either be due to effective insignificance or to econometric difficulties in isolating longer-term effects.

\subsection{THE ROLE OF OPEC}

As a last short discussion before starting our theoretical analysis, the role of the OPEC has to be enlightened so far as it is possible at this stage. The issue has lost importance in the most recent past but still appears in literature. Furthermore, OPEC strategies are subject to public policy debates (see, for example, Reed, 2014).

The organization was founded in 1960 and currently includes 12 countries: Algeria, Angola, Ecuador, Iran, Iraq, Kuwait, Libya, Nigeria, Qatar, Saudi Arabia, United Arab Emirates and Venezuela. This number was variable in the decades of OPEC's existence. According to the organization's own words, its mission is:

to coordinate and unify the petroleum policies of its Member Countries and ensure the stabilization of oil markets in order to secure an efficient, economic and regular supply of petroleum to consumers, a steady income to producers and a fair return on capital for those investing in the petroleum industry. (OPEC, 2015) 
In most publications outside of OPEC countries, the organization is simply denoted a 'cartel' (see, for instance, Griffin \& Vielhaber, 1994) aimed at controlling the global crude oil market. Bandyopadhyay (2009, pp.14-29) provides a helpful overview of a great volume of research contributions produced in the past four decades. The central questions of research are whether OPEC is really able to influence the oil price by means of cooperation between its member countries and the agreement on production quotas. Kaufmann et al. (2004) present evidence of Granger causality from OPEC utilization of production capacities and production quotas to the real oil price. Yet, they find no Granger causality in the opposite direction. On the other hand, Brémond et al. (2012) argue that OPEC has been acting as a price taker for most periods since 1973. Smith (2009, p. 152) differentiates by suggesting that OPEC has failed to agree on lower utilization of existing extraction capacities but has succeeded at limiting the building of capacities by constraining efforts to explore new reserves. According to Alhajji and Huettner (2000), it is not OPEC as a whole but rather Saudi Arabia as a single country that acts as a dominant producer.

There are numerous claims that OPEC's strength in affecting oil prices has overall decreased over the decades of its existence. For example, decreasing OPEC spare capacities, especially during the 1980s and again after 2002 may be seen as a sign of declining market power (see Bandyopadhyay, 2008 , p. 20). However, in contrast, it may well be considered a demonstration of strength rather than weakness of the workings of the OPEC cartel in Smith's (2009) sense, that the organization also agrees on the building of new capacities.

All in all, the literature remains inconclusive. The difficulty might be found in the complexity to model real-world strategic behaviour of a cartel like OPEC. Strategic behaviour is normally discussed in a microeconomic context. In the case of OPEC, however, it can be traced back to human decisions that have a more or less direct impact at the macroeconomic level. Therefore, there are probably even less linear, calculable and repeating effects than one might hope to find in other economic problems. As Bandyopadhyay (2009, p. 13) puts it, 'it is rather unusual to expect a rigid behavioural conduct from OPEC consisting of members with divergent views and interests. Thus, it would be unrealistic to predict the behavioural nature of the OPEC by making use of a single economic mode'.

A common approach, also adopted in this work, is to assume non-OPEC oil-producing countries as price takers (see, for instance, Kaufmann, 2011, p. 108). This means that oil companies in these countries behave like competitive firms in a global market, that is, a real market with its various imperfections that we will discuss later. As the average of studies characterizes OPEC neither as a perfect price maker nor as a perfect price taker, we 
have to be aware of a still unresolved problem when analyzing the global crude oil market. It does not make investigation impossible. However, a potential influence of strategic behaviour on the crude oil price - whatever its extent may be - tends to complicate the analysis.

\section{NOTE}

1. Barsky and Kilian (2004) argue that even the recessionary effects of the oil shocks of the twentieth century are overestimated in economic debates. 